\title{
Correction to: Developing an XGBoost model to predict blast-induced peak particle velocity in an open-pit mine: a case study
}

\author{
Hoang Nguyen ${ }^{1,2} \cdot$ Xuan-Nam Bui ${ }^{1,2} \cdot$ Hoang-Bac Bui ${ }^{3,4} \cdot$ Dao Trong Cuong ${ }^{5}$
}

Published online: 23 March 2021

(c) Institute of Geophysics, Polish Academy of Sciences \& Polish Academy of Sciences 2021

\section{Correction to: Acta Geophysica (2019) 67:477-490 https://doi.org/10.1007/s11600-019-00268-4}

In the original version of the paper, the authors used Fig. 1 to describe the study area's location. Unfortunately, some Vietnam's places have been missed in this figure because it is a small-scale map. Therefore, Fig. 1 is corrected as below:

The original article can be found online at https://doi.org/10.1007/ s11600-019-00268-4.

Hoang Nguyen

nguyenhoang@humg.edu.vn

1 Department of Surface Mining, Mining Faculty, Hanoi University of Mining and Geology, 18 Vien St., Duc Thang Ward, Bac Tu Liem Dist., Hanoi, Vietnam

2 Center for Mining, Electro-Mechanical Research, Hanoi University of Mining and Geology, 18 Vien St., Duc Thang Ward, Bac Tu Liem Dist., Hanoi, Vietnam

3 Faculty of Geosciences and Geoengineering, Hanoi University of Mining and Geology, 18 Vien St., Duc Thang Ward, Bac Tu Liem Dist., Hanoi, Vietnam

4 Center for Excellence in Analysis and Experiment, Hanoi University of Mining and Geology, 18 Vien St., Duc Thang Ward, Bac Tu Liem Dist., Hanoi, Vietnam

5 Ministry of Industry and Trade, Hanoi, Vietnam 


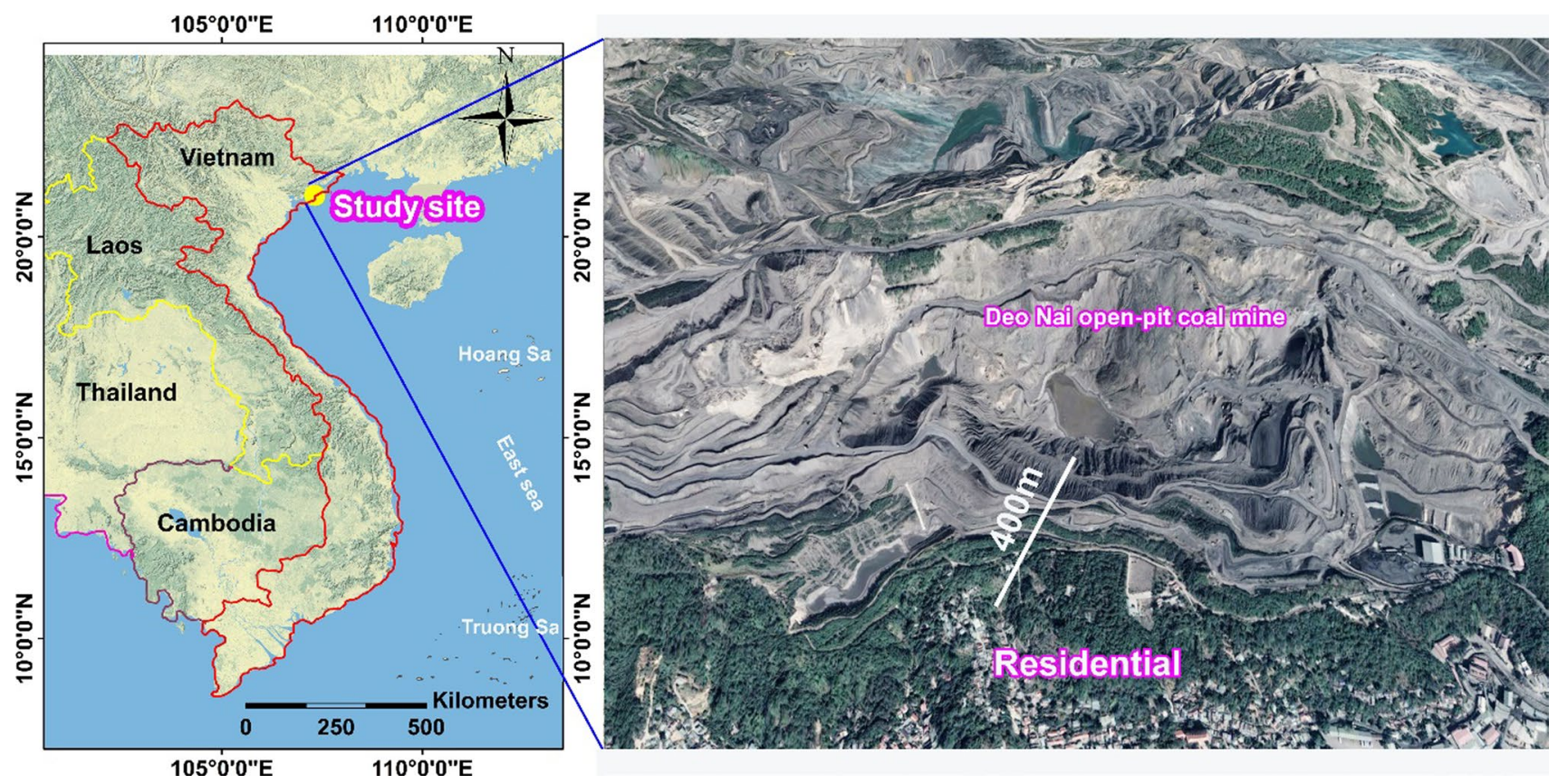

Fig. 1 Location of the study area 